\title{
Implications from Uranium-Series Disequilibria for the Origin of Detachment Faulting along the Mid- Atlantic Ridge, $24-30^{\circ} \mathrm{N}$
}

\author{
JULIET MESSER ${ }^{1}$, LYNNE J ELKINS ${ }^{1}$, YITONG LYU ${ }^{1,2}$, \\ LISA B KANT ${ }^{3}$, KENNETH WW SIMS ${ }^{3}$ AND CHARLES \\ LANGMUIR $^{4}$ \\ ${ }^{1}$ University of Nebraska-Lincoln \\ ${ }^{2}$ PetroChina Research Institute of Petroleum Exploration \& \\ Development \\ ${ }^{3}$ University of Wyoming \\ ${ }^{4}$ Harvard \\ Presenting Author: flodemedichi@gmail.com
}

Both spreading rates and local magma supply to mid-ocean ridges affect crustal construction styles and ridge morphology, alternately leading to either asymmetrical (detachment faulting) or symmetrical faulting styles. Uranium-series isotopic disequilibria in mid-ocean ridge basalts (MORB) may provide insight into how melt supply variations relate to ridges' accretion styles, a process not well understood. We use uranium-series disequilibria measured in young, unaltered basaltic glass from the Kane-Atlantis Supersegment $\left(24-30^{\circ} \mathrm{N}\right.$ MAR) to investigate the presence and origins of melt supply variations at both asymmetrical and symmetrical ridge segments using melt modeling calculations.

Preliminary $\mathrm{U}$ and $\mathrm{Th}$ concentration measurements suggest mean uranium concentrations are higher at symmetrical segments than asymmetrical segments, while mean $\mathrm{Th} / \mathrm{U}$ ratios are higher at asymmetrical segments [1].These concentrations might signal a more enriched melt supply under the symmetrical ridge segments, which suggests that heterogeneous source contributions from enriched mantle rocks may contribute higher magma quantities to the ridge axis, in turn helping to determine the faulting style at slow spreading rates [1]. Preliminary melt modeling predicts that enhanced melt contributions from enriched pyroxenitic mantle produces elevated $\left({ }^{230} \mathrm{Th} /{ }^{238} \mathrm{U}\right)$ in young basalts, due to higher garnet modes of pyroxenites throughout the melting regime. If symmetrical segments of the Kane-Atlantis Supersegment overlie more pyroxenite-rich mantle zones, we would expect measurably higher $\left({ }^{230} \mathrm{Th} /{ }^{238} \mathrm{U}\right)$ in basalts from those areas. Lack of such a systematic signature along symmetrical segments would alternatively suggest that melt supply variations along slow-spreading ridges are dominantly controlled by crustal magma pooling patterns, without an underlying mantle driving force.

[1] Lyu Y., Elkins L.J., Langmuir C., Sims K.W.W., \& Kant L. B., Implications from $U$ and $T h$ Concentrations for Drivers of Oceanic Crustal Construction along the Kane-Atlantis Supersegment, 24-30 N MAR (2019), Goldschmidt 2019, \#2096(abstr.). 